Article

\title{
Effects of Sample Preparation on Particle Size Distributions of Different Types of Silica in Suspensions
}

\author{
Rodrigo R. Retamal Marín ${ }^{1, *}$ (D), Frank Babick ${ }^{1}$, Gottlieb-Georg Lindner ${ }^{2}$, Martin Wiemann ${ }^{3}$ \\ and Michael Stintz ${ }^{1}$ (D) \\ 1 Research Group Mechanical Process Engineering, Institute of Process Engineering and Environmental \\ Technology, Technische Universität Dresden, Münchner Platz 3, D-01062 Dresden, Germany; \\ frank.babick@tu-dresden.de (F.B.); michael.stintz@tu-dresden.de (M.S.) \\ 2 Evonik Resource Efficiency GmbH, Brühler Straße 2, 50389 Wesseling, Germany; \\ gottlieb-georg.lindner@evonik.com \\ 3 IBE R\&D Institute for Lung Health gGmbH, Mendelstr 11, D-48149 Münster, Germany; \\ martin.wiemann@ibe-ms.de \\ * Correspondence: rodrigo.retamal@tu-dresden.de; Tel.: +49-351-463-35226
}

Received: 1 June 2018; Accepted: 19 June 2018; Published: 21 June 2018

\begin{abstract}
The granulometric characterization of synthetic amorphous silica (SAS) nanomaterials (NMs) still demands harmonized standard operation procedures. SAS is produced as either precipitated, fumed (pyrogenic), gel and colloidal SAS and these qualities differ, among others, with respect to their state of aggregation and aggregate strength. The reproducible production of suspensions from SAS, e.g., for biological testing purposes, demands a reasonable amount of dispersing energy. Using materials representative for each of the types of SAS, we employed ultrasonic dispersing (USD) at energy densities of $8-1440 \mathrm{~J} / \mathrm{mL}$ and measured resulting particle sizes by dynamic light scattering and laser diffraction. In this energy range, USD had no significant impact on particle size distributions of colloidal and gel SAS, but clearly decreased the particle size of precipitated and fumed SAS. For high energy densities, we observed a considerable contamination of SAS suspensions with metal particles caused by abrasion of the sonotrode's tip. To avoid this problem, the energy density was limited to $270 \mathrm{~J} / \mathrm{mL}$ and remaining coarse particles were removed with size-selective filtration. The ultrasonic dispersion of SAS at medium levels of energy density is suggested as a reasonable compromise to produce SAS suspensions for toxicological in vitro testing.
\end{abstract}

Keywords: nanomaterials (NMs); nanostructured; synthetic amorphous silica (SAS); ultrasonic dispersing (USD); energy density; sample preparation; in vitro testing

\section{Introduction}

Modification of physico-chemical properties of nanomaterials (NMs) or nanostructured materials allows the control and variation of design, development and improvement of new products. Synthetic amorphous silica (SAS) comprise an important group of NMs, which are added to industrial as well as consumer products such as cosmetic or foods [1-7] within which they serve e.g., as stabilizers, thickeners, pigments, flow enhancing agents, or UV absorbers [3,8-10]. Based on some concern regarding possible health impacts and safety risks of NMs, legal authorities request the toxicological analysis of SAS NMs by means of in vivo and in vitro studies [11-15].

Generally, ultrasonic dispersing or separation has been used for sample preparation of nanomaterials for safety assessment [16]. These studies can support the optimization of nanosynthesis or nano-applications for the sake of a "Green Synthesis of Nanomaterials". One example for such 
green nano-application of amorphous silica in entomology and parasitology as a nanopesticide has been considered safe for humans because of the specific mechanisms of action [17].

An important aspect of exposure and toxicological analyses is the characterization of NMs with respect to particle size. Most SAS occur in an aggregated state with particle sizes ranging from nanometer-sized primary particles to micrometer-sized aggregates or agglomerates [18-20]. However, the sample preparation for a specific in vitro test should consider the particle size-distribution which is of relevance for a given exposure pathway [21-24]. For example, inhalation of particles into the human respiratory tract leads to a fractionation of particles: larger agglomerates are deposited in the nasopharyngeal region $(5-30 \mu \mathrm{m})$, small agglomerates are partially deposited in the tracheobronchial region $(1-5 \mu \mathrm{m})$, and only small $(<1 \mu \mathrm{m})$ and nano-sized materials $(1-100 \mathrm{~nm})$ may penetrate into the alveolar region of the lung [25-30]. Thus, toxicity testing of NMs using in vitro lung models demands the preparation of properly suspended samples under defined conditions.

In general, studies on environmental and health risk assessment focus on transport and deposition of NMs in real-life exposure scenarios. Both processes are governed by the mobility of aggregates and agglomerates, for which reason the size of aggregates and agglomerates needs to be measured. This is different from the nanomaterial definition recommendation of the European Commission, which is based on number-weighted distribution of the minimum size of isolated particles or constituent particles within aggregates and agglomerates [31,32].

The analysis of nanomaterials (NMs) and nanostructured materials requires standard operation procedures (SOPs) for the preparation of suspension samples to ensure defined granulometric states [33-35]. Therefore, the preparation and analysis of nanomaterial suspensions needs a high degree of standardization with respect to primary sample preparation (stock suspension), secondary sample preparation, conditioning (e.g., adjusting suspension composition or concentration), sample splitting and finally measurement/interpretation. All these steps need to be considered for the characterization of liquid-suspended powders and for the comparison of different SOPs in view of their reproducibility. Although wetting and low energy dispersion of SAS powders in the suspension are substantial components of (primary) sample preparation, further ultrasonic dispersing (USD) is needed as it is the most versatile method to disintegrate large particle agglomerates into small particle aggregates or primary particles. At the same time, stabilization and homogenization of the dispersed particles are necessary.

USD is a rather intense type of dispersing, which relies on the hydrodynamic stress caused by collapsing cavitation bubbles. As USD can be performed with different types of equipment (e.g., ultrasonic bath, high-power probe sonicator, or cup-horn sonication) methods ensuring its reproducibility are mandatory. Several studies have shown that the energy density (measured in $\mathrm{J} / \mathrm{mL}$ ) serves as a well-suited parameter for obtaining a largely identical degree of USD of nanomaterials among different laboratories $[23,36,37]$. Of note, the application of different ultrasonic dispersing methods (e.g., variation of the sonotrode geometry) and parameter settings (e.g., sonication time and vibration amplitude) requires the application of the energy density concept, applicable to ultrasonication, rotor-stator systems [37,38] or high-pressure dispersing [39-41]. In all these cases, the ultrasonic dispersing energy density can be used as a main parameter for comparing available and new sample preparation protocols or SOPs.

To achieve a reproducible particle size analysis, it is necessary to use adequate sample preparation techniques. The USD facilitates the disintegration of submicron agglomerates, which are therefore of special relevance for the preparation of stable and homogeneous distribution of particles in the suspension and contribute to achieve a stable dispersion. The particles are under interaction of different dispersion forces which control their random dispersion in the sample volume. The energy density has been used in Table 1 to compare several studies, which are developed for the application to nanostructured materials). 
Table 1. Published protocols of ultrasonic dispersing (USD) specifically designed for application to nanostructured materials; characteristic parameters including the (range of) inserted energy density.

\begin{tabular}{cccc}
\hline Protocol & Sample Volume & Dispersing Time & (Calorimetric) Energy Density \\
\hline Tantra 2016 [42]; Pradhan 2016 [43] & $6 \mathrm{~mL}$ & $16 \mathrm{~min}$ & $1176 \mathrm{~J} / \mathrm{mL}$ \\
Rasmussen et al., 2013 [35] & $15 \mathrm{~mL}$ & $10 \mathrm{~min}$ & $500-400 \mathrm{~J} / \mathrm{mL}$ \\
Taurozzi et al., 2012 [44] & $10 \mathrm{~mL}$ & $16 \mathrm{~min}$ & $2500 \mathrm{~J} / \mathrm{mL}$ \\
Jensen et al., 2011 [33] & $50 \mathrm{~mL}$ & $5 \mathrm{~min}$ & $300 \mathrm{~J} / \mathrm{mL}$ \\
Bihari et al., 2008 [45] & $6 \mathrm{~mL}$ & $16 \mathrm{~min}$ & $3140 \mathrm{~J} / \mathrm{mL}$ \\
Mandzy et al., 2005 [46] & $1 \mathrm{~mL}$ & $1 \mathrm{~min}$ & $420 \mathrm{~J} / \mathrm{mL}$ \\
Pohl et al., 2005 [37] & - & Time frames $(2 \mathrm{~h})$ & $5700 \mathrm{~J} / \mathrm{mL}$ \\
Pohl et al., 2004 [47] & $10-42 \mathrm{~mL}$ & $17-630 \mathrm{~s}$ & $400-30,000 \mathrm{~J} / \mathrm{mL}$ \\
\hline
\end{tabular}

Table 1 shows that the energy densities used in several recent studies to disperse nanomaterials differ by more than two orders of magnitude. This raises the question, as to which extent they influence the results of particle size measurement. Previous studies on different grades of $\mathrm{NMs}$ such as $\mathrm{SiO}_{2}, \mathrm{Al}_{2} \mathrm{O}_{3}$, or $\mathrm{TiO}_{2}$ have shown that even with a comparatively high energy density of up to $5 \mathrm{~kJ} / \mathrm{mL}$ a maximum dispersion cannot be achieved for all materials [20]. However, as administration of such energy densities requires extensive cooling of the samples and prolonged periods of ultrasonic treatment, we were seeking for a reasonable compromise to achieve an acceptable dispersion of nanomaterials.

In this paper, we examine the effect of USD energy on the dispersion of SAS and characterize resulting particle size distributions (PSD). Despite their identical chemical composition, SAS products show considerable variations with respect to the synthetic routes, particle morphology, and product properties. The synthesis of silica is realized either in aqueous solution based on sodium silicate solution or in gaseous phase from $\mathrm{SiCl}_{4}[48,49]$. The types of silica originating from silica synthesis processes in aqueous solution are silica gel (SG), precipitated silica (PS) and colloidal silica (CS). Fumed silica (FS), also referred to as pyrogenic silica, is synthesized from gaseous phase. SAS products are nanostructured NMs [46] as they consist of aggregates and agglomerates of nanosized constituent particles (FS, PS and SG, cf. [50]) or well-dispersed nano-objects (CS). Accordingly, the preparation of suspensions of FS, PS and SG requires defined dispersion procedures for their use, e.g., in toxicity studies, and characterization, whereas this is not really necessary for colloidal silica $[19,20]$. Furthermore, the different types of silica have a characteristic morphology due to their varied synthetic processes. This is an important issue that needs to be considered for comparison and data interpretation (e.g., reproducibility, effectiveness).

\section{Materials and Methods}

\subsection{Materials}

This study analyzed SAS products, representative for FS, PS, SG and CS, respectively. While FS, PS, SG were provided as untreated hydrophilic powders, CS was provided as an aqueous suspension. Important physico-chemical properties are summarized in Table 2.

Table 2. SAS properties.

\begin{tabular}{cccccc}
\hline $\begin{array}{c}\text { SAS Type } \\
\text { Internal Code }\end{array}$ & Fumed Silica & Precipitated Silica & \multicolumn{2}{c}{ Silica Gel } & \multicolumn{2}{c}{ Colloidal Silica } \\
BET & \multicolumn{1}{c}{$\left(\mathrm{m}^{2} / \mathrm{g}\right)$} & P-2 & 440 & 700 & $200^{2}$ \\
$\mathrm{BH}^{3}$ & 300 & - & - & 40 \\
solid content for suspensions (wt.- $\%)$ & - & 6.5 & 4.4 & 9.7 \\
electric conductivity $(\mu \mathrm{S} / \mathrm{cm})$ at $25^{\circ} \mathrm{C}$ & 4 & 160 & 55 & 4771.6 \\
\hline
\end{tabular}

${ }^{1}$ BET: Surface measured according to Brunauer, Emmet and Teller [51,52]. ${ }^{2}$ measured from freeze dried material.

${ }^{3}$ suspended in ultra-pure water $\left(1\right.$ wt.- $\left.\%, 25^{\circ} \mathrm{C}\right)$. 
Figure 1a-c show SEM (JEOL Ltd, Tokyo, Japan) images of typical aggregates of FS, PS and SG [50]. In contrast, CS (Figure 1d) contains isolated spherical nanoparticles, which have gathered into an agglomerate-like structure upon drying on the TEM grid.

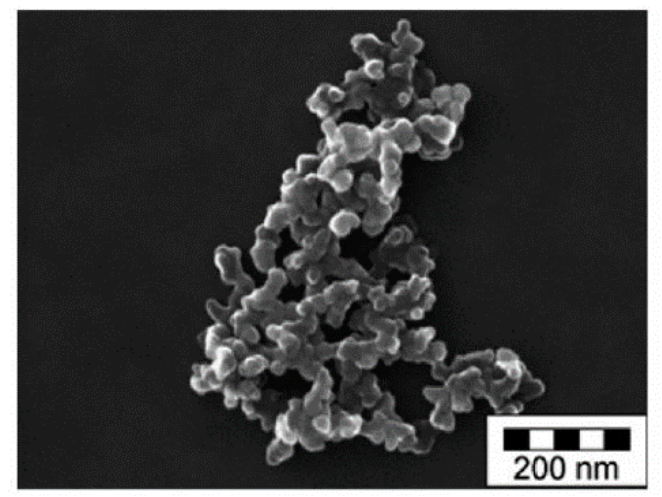

(a)

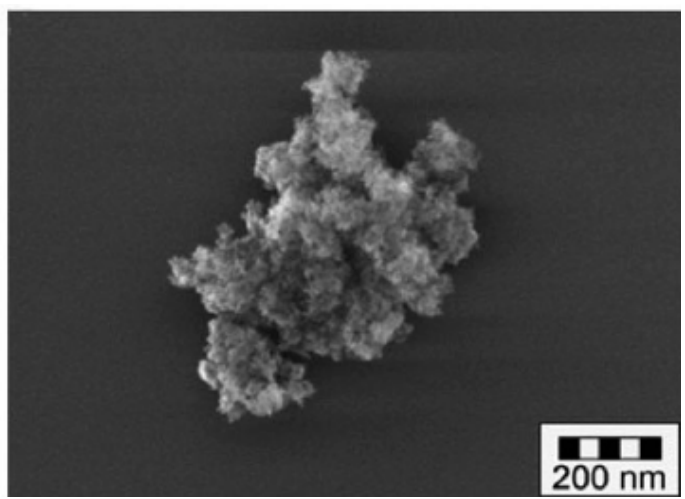

(c)

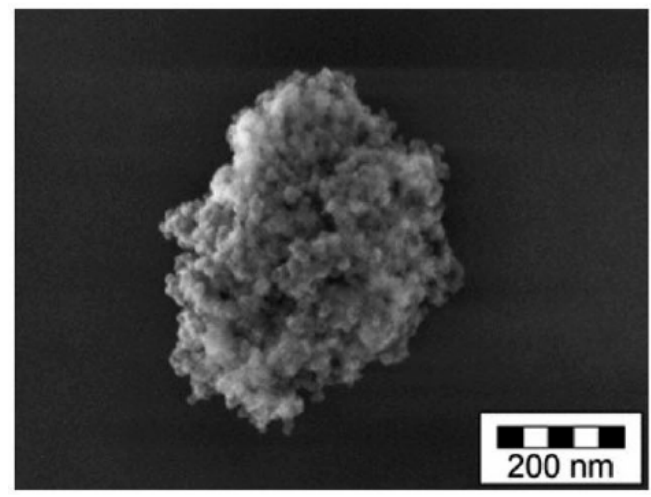

(b)

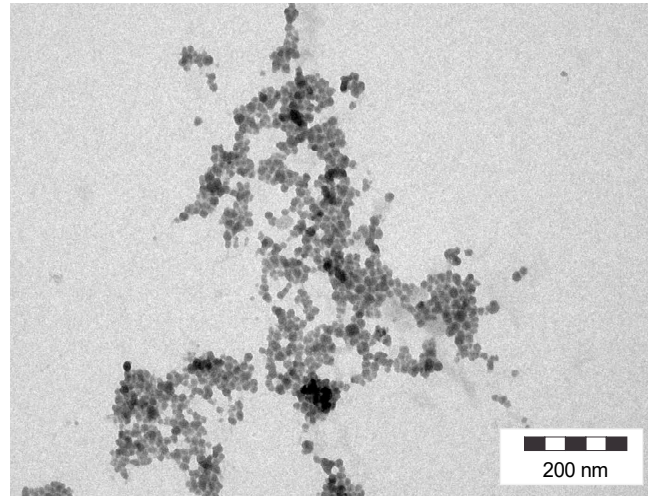

(d)

Figure 1. SEM and TEM images of different silica types. (a) fumed (pyrogenic) silica (opened fractal-like aggregates), (b) precipitated silica (compact fractal-like aggregates), (c) silica gel (compact and microporous fractal-like aggregates) and (d) colloidal silica (isolated spherical nanoparticles or small aggregates, here dried on TEM grid to opened agglomerates).

\subsection{Instruments and Procedures for Sample Preparation}

To prepare stock suspensions of SAS $1 \mathrm{wt}$.- $\%$ of silica powders (FS, PS, SG) were dispersed in $100 \mathrm{~mL}$ de-ionized water $(18.3 \mathrm{M} \Omega \mathrm{cm}, 0.2 \mu \mathrm{m}$ filtered $)$. To avoid re-agglomeration, the particles were placed in a liquid environment that ensured high surface charges. The $\mathrm{pH}$ value of prepared silica suspension is far from the isoelectric point of silica (e.g., $\mathrm{pH}$ 1.8-2.5) and it has a low electric conductivity (see Table 2) [53-55]. Powders were dispersed by different treatments: Firstly, by means of a paddle stirrer (PS) (model RW 11 basic, IKA, Staufen, Germany), which administered the lowest input of mechanical energy into the suspension and which was used for the homogenization of SAS suspensions. Of note, the geometric size of the paddle stirrer and the sample beaker as well as stirring velocity ensured hydrodynamic equivalence to the "paddle apparatus" specified in Ph. Eur. 5.7. (2006) [56]. Secondly, by means of a turbulent shear rotor stator (RS) (Ultra-Turrax T25, IKA) which was used to achieve advanced dispersion and to investigate changes of PSD of different SAS types upon progressive dispersion energy. The RS provides shear forces, which cause shear stress on particle agglomerates. Thirdly, by means of immersion horns (three different instruments, see Table 3) which were used in most experiments [33-35]. The sonotrode or horn is in direct contact with the suspension and the dispersion effect is associated to cavitation, which occurs in highly intensive sound fields. Furthermore, the cavitation causes the formation of vapor cavities in a liquid (bubbles) which steadily grow to a critical size, at which they turn instable and implode [20]. This implosion produces 
high temperature and rapid micro-jets, which exert mechanical stress to the particles close to the formed bubble [57]. This mechanical stress leads to the fragmentation or at the least to the erosion upon the direct contact with the imploding cavities [58,59].

The USD equipment consisted of three different instruments equipped with different sonotrodes (a few mm up to a few $\mathrm{cm}$ ) (see Table 3), which were operated at frequencies in the range of $20 \mathrm{kHz}$ to $100 \mathrm{kHz}$. Instruments had a nominal power consumption of a few Watt to approximately $1 \mathrm{~kW}$ [18]. The calorimetric energy input was measured at different dispersing instruments. Most of them work at frequencies in the range of $20 \mathrm{kHz}$. In pilot experiments, various tip diameters of the sonotrodes were selected according to the geometry of the beaker and the sample volume required by the sample preparation protocols.

Table 3. Technical data of ultrasonic dispersion instruments operated at approximately $20 \mathrm{kHz}$.

\begin{tabular}{cccc}
\hline Model & Vibra-Cell 72412 $^{\mathbf{1}}$ & UDS751 $^{\mathbf{2}}$ & SONIFIER 450D $^{\mathbf{3}}$ \\
\hline Code & $\mathbf{V}$ & $\mathbf{T}$ & B \\
\hline company & Sonics and Materials & Topas GmbH & Branson Ultrasonics \\
normal capacity $(\mathrm{W})$ & 600 & 200 & 400 \\
tip diameter $(\varnothing, \mathrm{mm})$ & 1319 & 3714 & 513 \\
amplitude $(\%)$ & $0-100$ & $0-100$ & $10-100$ \\
\hline
\end{tabular}

\footnotetext{
${ }^{1}$ Vibra-Cell 72412 (Sonics \& Materials, Newtown, CT, United States). ${ }^{2}$ UDS751 (Topas GmbH, Dresden, SN, Germany).

3 SONIFIER 450D (Branson Ultrasonic Corporation, Danbury, CT, United States).
}

For the particle size analysis of all silica types in this study one USD equipment was selected, the generator Vibra-Cell 72412 (Sonics and Materials; $20 \mathrm{kHz}$, nominal power: $600 \mathrm{~W}$ together with a $19 \mathrm{~mm}$ tip diameter solid probe. The tip of the probe was replaced for each series of dispersing experiments. USD was performed at maximum amplitude $(100 \%)$ in a pulsed mode $(2 \mathrm{~s}: 2 \mathrm{~s})$ with the probe being uniformly immersed in the sample. The same type of glass beaker was employed for all samples; the beakers were placed in cooled water during the USD. Even though, samples were steadily heated-up with ongoing USD, for which reason the USD was interrupted after a maximum of 4 min to cool down the complete the sample and the ultrasonic probe. This procedure ensured that the sample temperature stayed below $33^{\circ} \mathrm{C}[20]$.

\subsection{Instruments for Particle Size Analysis}

USD leads to deagglomeration and disintegration of aggregates and the corresponding change in the granulometric state was quantified by laser diffraction (LD) and dynamic light scattering (DLS). However, these standard analytical techniques are based on mathematical models, which are not perfectly applicable to the examined particle systems, e.g., because they assume spherical particles (e.g., Stokes-Einstein relation and Mie theory for DLS), or because they do not cover the whole size range of broad distributions (e.g., Fraunhofer diffraction theory for LD) [18-20,60,61]. To avoid these technical limitations and for a better interpretation of measured data it is advantageous to apply both techniques to well-adapted dilutions of the same sample.

LD measurements were carried out with a HELOS KR (Sympatec, Clausthal-Zellerfeld, Germany) for angular ranges below $35^{\circ}$ (i.e., forward scattering). Within this study an angular range of $0.1^{\circ}$ to $9^{\circ}$ (measurement range R3) was used, which is sensitive for particles of $0.5 \mu \mathrm{m}$ to $175 \mu \mathrm{m}$, but which is insensitive to nanoparticles $(x \leq 100 \mathrm{~nm})$. These measurements were rather insensitive to small, weakly scattering particles $<<1 \mu \mathrm{m}$.

To quantify particle sizes in sub-micrometer range, DLS measurements were conducted. The employed instrumentation, HPPS (Malvern, UK), bases on backscattered $\left(173^{\circ}\right)$ and sideward scattered light, respectively. Measured DLS signals (i.e., autocorrelation functions) were analyzed with inversion procedures, which compute complete size distributions, and cumulant analysis. The latter yields a polydispersity index, PDI, and a characteristic mean particle size, xcum, which is the harmonic 
mean of the intensity-weighted size distribution. The samples are filled in closed cuvettes (4 mL), which are placed in the temperature-controlled sample holder at least 15 min before the measurements.

\subsection{Estimation of the Calorimetric Energy Input}

The effectivity of the ultrasonication, in comparison with other dispersion procedures regarding size reduction, demands the necessity to evaluate the applied acoustic energy per unit suspension volume $\left(E_{V}\right)[18,20,23,37,46]$. The calculation of ultrasonic dispersion energy cannot be calculated directly. There are two ways to estimate the inserted acoustic energy. One way is the estimation from electrical energy consumption $\left(E_{V, \mathrm{el}}\right)$ and the other possibility is through the generated heat after implosion of bubbles $\left(E_{V, \mathrm{cal}}\right)$. The electrical energy consumption depends on many factors: transformation of energy of ultrasonic dispersions instruments (e.g., normal capacity, range of frequencies, types and probe diameter) that must be considered for comparison and validation. Furthermore, another important point to consider is the acoustic reflections inside the probe depending on, for example, sample volume, density and the propagation velocity of sound of liquid (acoustic impedance) [62].

This study uses the calorimetric energy input as decisive parameter for the effect of USD. Therefore, the USD devices needed to be calibrated regarding the calorimetric power input for the setup and settings (sample volume, horn diameter; nominal ultrasonic amplitude) employed in dispersing the SAS samples. The calibration comprises the evaluation of temperature increase by ultrasonication of a defined volume of de-ionized water. In this study, USD was conducted at $100 \mathrm{~mL}$ suspension sample placed in a $150 \mathrm{~mL}$ cylindrical borosilicate beaker. Please note that other studies worked with higher volumes (e.g., $500 \mathrm{~mL}$, [23,34]) or smaller ones (e.g., $6 \mathrm{~mL}[33,42,43])$. A further difference to other studies is that the beaker was placed in insulating foam, to minimize heat exchange with environment. The whole setup, including the ultrasonic probe as well as a thermometer with short response-time, was allowed to thermally equilibrate. Then ultrasonication was started and the temperature within the beaker was recorded as function of time.

The calorimetric energy input into a suspension sample by ultrasonication can be calculated from the heat production rate $P_{\text {cal }}$ which is a function of the dispersion time $t_{\text {disp. }}$. The former parameter is valid for defined conditions of ultrasonication, i.e., for defined sample properties and USD settings. It can be determined by specifically designed experiments that measure the temperature increase when sonicating the particle-free dispersion medium (e.g., water). Furthermore, it is necessary to consider the mass and specific heat of the beaker to have a correct determination of heat production and to evaluate the initial slope of temperature increase, which needs to be less than 4 Kelvin $(\Delta T \leq 4 \mathrm{~K})$. Furthermore, the following proposed equation to estimate the calorimetric energy input assumes that the sonotrode has a zero heat capacity and that there is no heat exchange with the environment:

$$
P_{\mathrm{cal}}=\left(m_{w} c_{\mathrm{p}, \mathrm{w}}+m_{b} c_{\mathrm{p}, \mathrm{b}}\right) \cdot \Delta T / t_{\mathrm{disp}}
$$

where $m_{w}$ denotes the mass of liquid, $m_{b}$ denotes the mass of beaker, $c_{\mathrm{p}, \mathrm{w}}$ specific heat of water, $c_{p, b}$ specific heat of beaker, $\Delta T$ the temperature increase and $t$ the dispersion time [63,64]. The calorimetric energy density can be determined as follows:

$$
E_{V, \mathrm{cal}}=\frac{P_{\mathrm{cal}} \cdot t_{\mathrm{disp}}}{V}=\left(m_{W} c_{\mathrm{p}, \mathrm{W}}+m_{B} c_{\mathrm{p}, \mathrm{B}}\right) \cdot \Delta T / V
$$

with $V$ being the suspension volume.

The energy density is considered to be a most important process parameter when dispersing suspensions and emulsions. Frequently, a power-law relationship can be established between average particle size $x$ and energy density $E_{V \text {,cal }}$ (e.g., [47]):

$$
\bar{x} \propto E_{V, \text { cal }}^{-b}
$$


where "average particle size" can be any characteristic distribution parameter (e.g., median size or arithmetic mean) referring to a defined type of quantity, in which the size distribution is weighted (e.g., number, volume or scattering intensity). The exponent $b$ describes the material's dispersibility under the specified conditions.

Finally, there are some assumptions to estimate values for calorimetric calibration of ultrasonic instruments. The first assumption is the uniform temperature of water and beaker, second-zero heat capacity of ultrasonic probe and third-no heat transfers out of the system beaker-water.

\section{Results and Discussion}

\subsection{Calorimetric Calibration of Probe Sonication}

While the ultrasonic wave propagates through the dispersion medium, its energy is absorbed and converted into heat $[65,66]$. Figure 2 exemplifies this progressive heating during USD for a non-insulated beaker. The images give an impression of how the heat generated upon ultrasonication is transferred from the sonotrode into the surrounding medium and associated masses. Therefore, it is important to consider some issues such as sample volume, or isolating foam to achieve a correct calorimetric calibration of probe sonication, as explained in the proposed protocol (see Section 2.4).

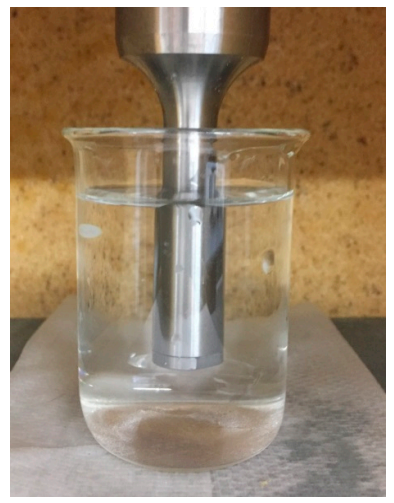

(a)

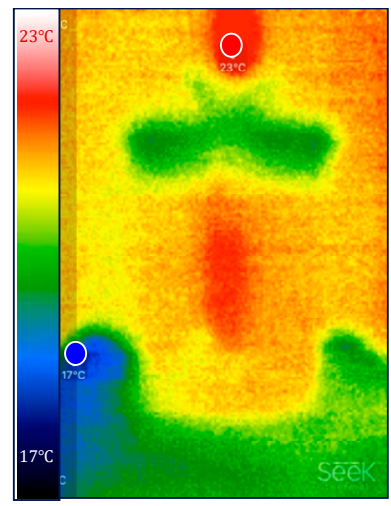

(c)

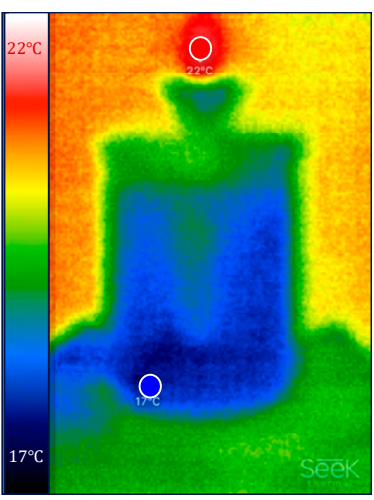

(b)

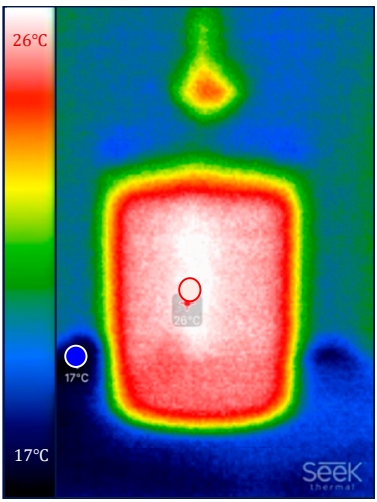

(d)

Figure 2. Progressive heating of the sonotrode, sample fluid, and beaker in the course of USD. Images were captured with a thermal imaging camera (Seek Thermal) after different dispersing periods; $(\mathbf{a}, \mathbf{b}): 0 \mathrm{~s},(\mathbf{c}): 30 \mathrm{~s},(\mathbf{d}): 60 \mathrm{~s}$. Temperature (in degree Celsius) is shown on a pseudo-color scale whose range was automatically adjusted to the temperature peak $\left(\mathrm{T}_{\min } / \mathrm{T}_{\max }\right)$ of the measurement (i.e., (a) $17^{\circ} \mathrm{C} / 22^{\circ} \mathrm{C}$, (b) $17^{\circ} \mathrm{C} / 23^{\circ} \mathrm{C}$, (c) $17^{\circ} \mathrm{C} / 26^{\circ} \mathrm{C}$ ).

The calorimetric calibration was calculated for different ultrasonic dispersing instruments (according to the protocol in Section 2.4) to compare their heat production after setting of different parameters (see Section 2.2). The calorimetric measurements delivered the results in Figure 3. 


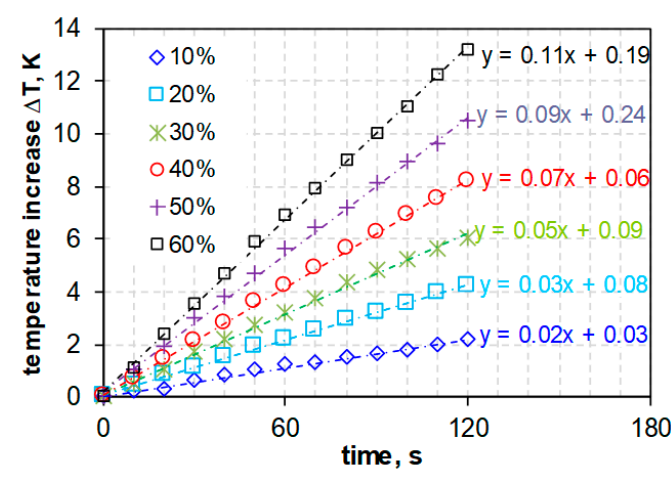

(a)

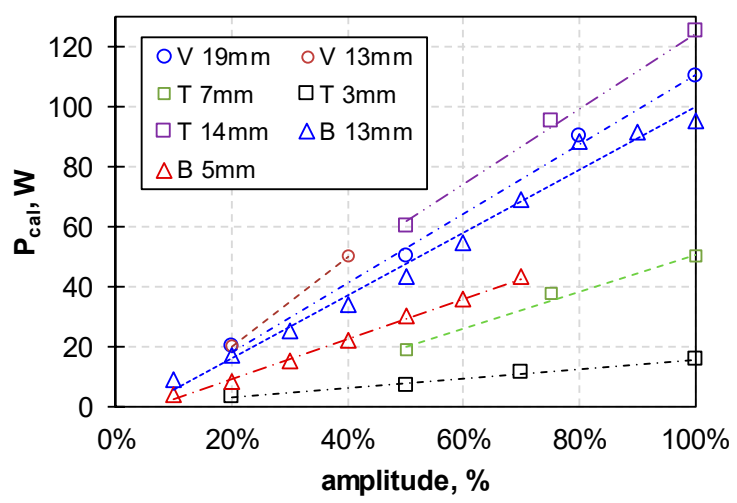

(b)

Figure 3. Calorimetric calibration curves of ultrasonic dispersing instruments. (a) temperature increases $(\Delta T)$ in Kelvin (K) over time, obtained with a $13 \mathrm{~mm}$ tip diameter sonotrode (Branson 450D) and increasing amplitudes (10-60\% from maximum, as indicated in the graph). (b) Heat production $\left(P_{\text {cal }}, \mathrm{W}\right)$ of the different dispersing instruments and sonotrode geometries Vibra-Cell 72412 (V), Topas UDS751 (T) and Branson SONIFIER 450F (B) (outlined in Table 3) as a function of increasing amplitude (in \% from maximum).

\subsection{Sample Preparation by Probe Sonication}

\subsubsection{Impact of USD on Particle Size Distribution of SAS}

Previous studies have shown that the PSD of, e.g., FS may be highly polydisperse $[20,54])$ and covers a wide range from of a few nanometers up to several micrometers [18-20]. As outlined above (Section 2.3), the appropriate granulometric analysis of such samples requires a combination of LD and DLS. This section addresses the effectiveness of ultrasonic dispersing on particle size of silica types measured with both techniques.

Suspensions of the SAS types were prepared by a combination of dispersing procedures and defined calorimetric energy densities $(\mathrm{EV}, \mathrm{J} / \mathrm{mL}$ ). Depending on the instrumentation (see Section 2.3) dispersing energies were weak from propeller stirrer (PS), moderate from rotor-stator (RS), or intense from ultrasonication (US, different dispersing energies) and the selected calorimetric energy densities' values are based on the calorimetric calibration of probe sonication (see Figure 3). The calorimetric energy density of the US treatment ranged from $8 \mathrm{~J} / \mathrm{mL}$ through $18 \mathrm{~J} / \mathrm{mL}$ and $270 \mathrm{~J} / \mathrm{mL}$ to a maximum energy input of $1440 \mathrm{~J} / \mathrm{mL}$. This stepwise increase of energy input allows for a comprehensive characterization of SAS with respect to particle size and morphology.

Figures 4-6 show the LD measurements of the PSD results of the transformed distribution density of upon increasing $E_{V \text {,cal }}$ for PS, FS, and SG (see Section 2.1). The transformed distribution density represents in accordance with ISO 9276-1:1998 provide the differential size distribution on a log scaled abscissa. Areas under the curve represent the volume portions of the size classes [67]. The result of a long-term sedimentation of silica suspensions (after five months) is shown in parallel.

Precipitated silica (PS, $400 \mathrm{~m}^{2} / \mathrm{g}, 1 \mathrm{wt} . \mathrm{\%}$ ) shows a clear tendency of deagglomeration by increasing dispersion energy (Figure 4a). Especially the presence of coarse, micrometer-sized agglomerates was diminished, and this effect started mostly at $18 \mathrm{~J} / \mathrm{mL}$. In line with these results the sedimentation profiles of ultrasonicated PS suspensions show an increasing degree of opacity upon $270 \mathrm{~J} / \mathrm{mL}$ and $1440 \mathrm{~J} / \mathrm{mL}$ (Figure 4b), suggesting the presence of slowly settling, light scattering particles in the sub-micrometer range. However, although the zone of opacity was wider upon $1440 \mathrm{~J} / \mathrm{mL}$, the volume of the white matter at the bottom was similar.

Largely similar to PS was fumed (pyrogenic) silica (FS, $300 \mathrm{~m}^{2} / \mathrm{g}, 1 \mathrm{wt}$ - $\%$ ) deagglomerated by increasing USD energy (Figure 5a). The deagglomeration of large particles was achieved already with a moderate dispersion (RS) and increased further upon administration of USD energy. Interestingly, 
the mono-modal PSD of FS became bimodal upon 18, 270, and $1440 \mathrm{~J} / \mathrm{mL}$, such that a fine and a large fraction could be distinguished (Figure 5a). Of note, the large fraction generated by $270 \mathrm{~J} / \mathrm{mL}$ and $1440 \mathrm{~J} / \mathrm{mL}$ comprised larger particles as compared to the fraction induced by $18 \mathrm{~J} / \mathrm{mL}$. This suggests that elevated energy levels at least in part can provoke an agglomeration of FS. The effect was most obvious at an USD energy of $270 \mathrm{~J} / \mathrm{mL}$. These results confirm previous studies, where the coarser particles appeared at energy density levels above $171 \mathrm{~J} / \mathrm{mL}$ [20]. The sedimentation profiles of FS at higher dispersion energies showed a similar degree of opacity in the supernatant, but an increased volume of the white sediment. This suggests that high USD energy leads to the formation of larger particles from the same mass of FS (see Figure $5 b$ ).

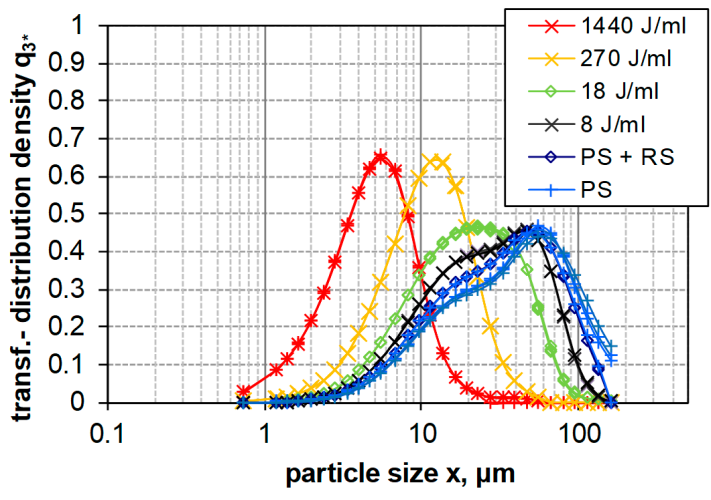

(a)

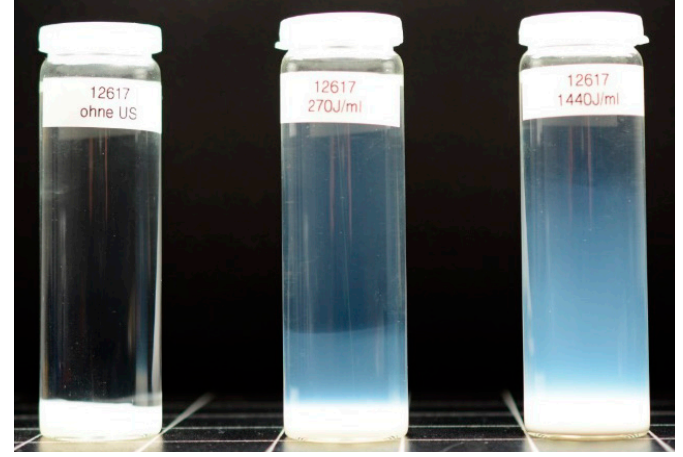

(b)

Figure 4. Particle size distribution of PS $\left(440 \mathrm{~m}^{2} / \mathrm{g}\right)$ dispersed by different procedures. (a) Size distribution measured by laser diffraction spectroscopy plotted as the transformed distribution density $\left(\mathrm{q}^{3 *}\right)$. Weak (PS), moderate (RS) and intense (US) dispersion with increasing ultrasonic energies (indicated in the diagram) were employed. (b) Silica suspensions after five months (left $1 \mathrm{~J} / \mathrm{mL}$, middle $270 \mathrm{~J} / \mathrm{mL}$, and right $1440 \mathrm{~J} / \mathrm{mL}$ ).

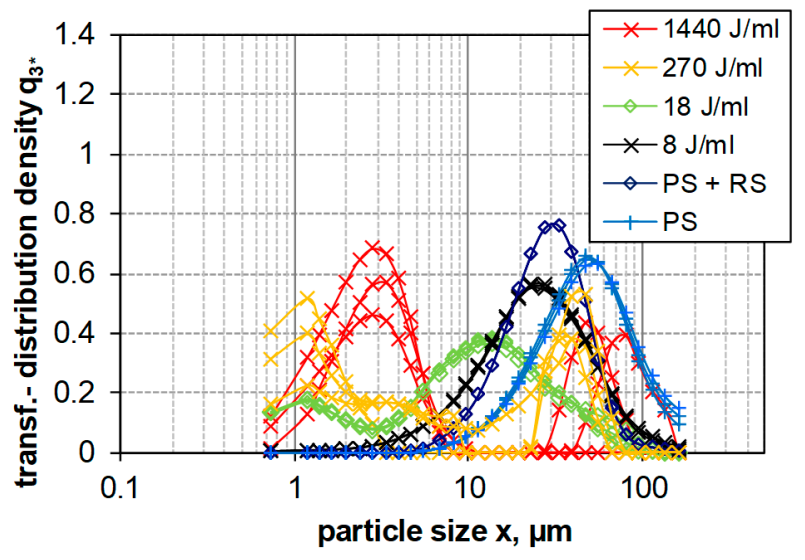

(a)

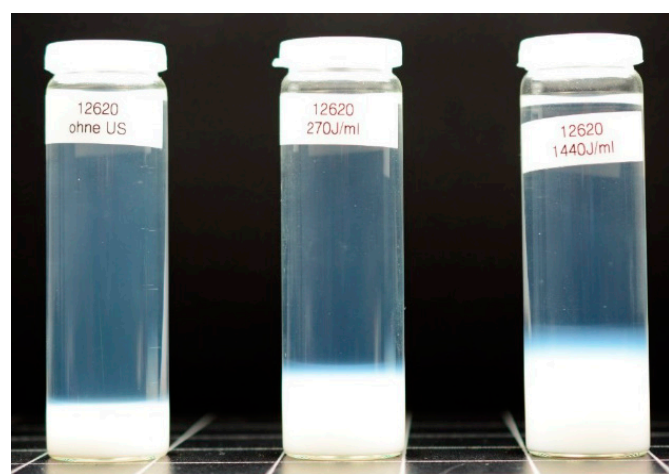

(b)

Figure 5. Particle size distribution of FS $\left(300 \mathrm{~m}^{2} / \mathrm{g}\right)$ dispersed by different procedures. (a) Size distribution measured by laser diffraction spectroscopy plotted as the transformed distribution density $\left(\mathrm{q}^{3 *}\right)$. Weak (PS), moderate (RS) and intense (US) dispersion with increasing ultrasonic energies (indicated in the diagram) were employed. (b) Silica suspensions after five months (left $1 \mathrm{~J} / \mathrm{mL}$, middle $270 \mathrm{~J} / \mathrm{mL}$, and right $1440 \mathrm{~J} / \mathrm{mL}$ ).

As can be seen in Figure 6a, the PSD of silica gel (SG, $700 \mathrm{~m}^{2} / \mathrm{g}, 1 \mathrm{wt} .-\%$ ) remained unchanged upon increasing energy density. SG consists of compact (dense) and microporous fractal-like aggregates (see Figure 1), which appear to be insensitive to high USD energies and undergo a rapid sedimentation of particles (by median $x_{50,3}=6 \mu \mathrm{m}$ ), irrespective of USD treatment (see Figure $6 \mathrm{~b}$ ), although both 
ultrasonic treatments led to a similar degree of opacity of the supernatant which may be indicative of smaller particles (not measurable by LD).

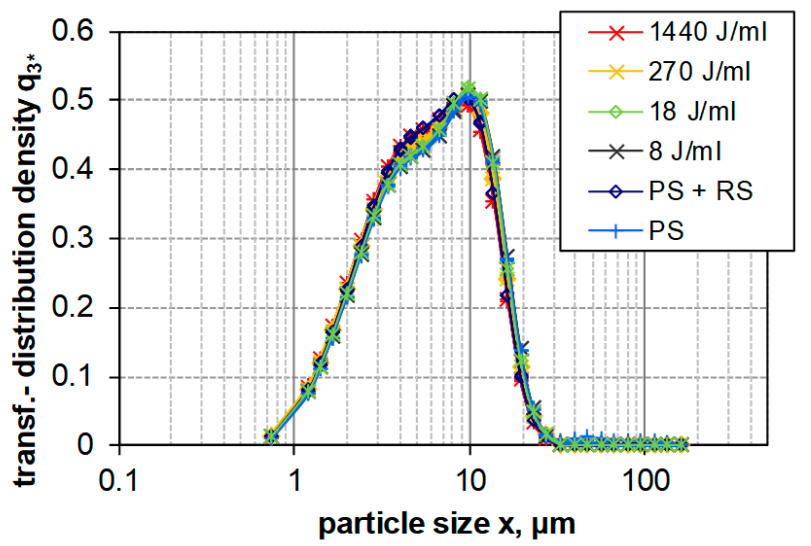

(a)

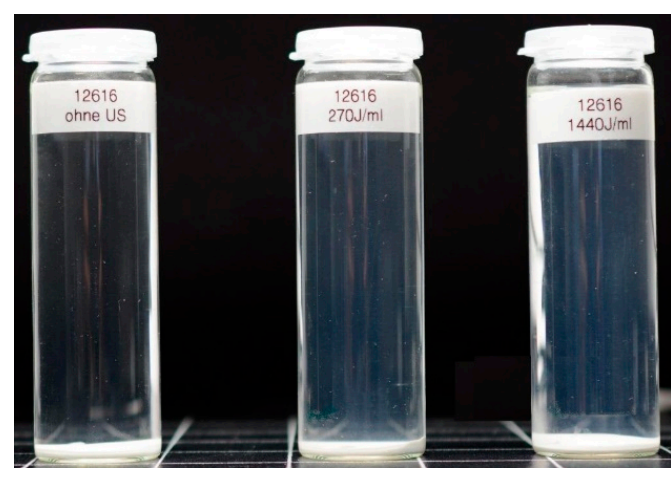

(b)

Figure 6. Particle size distribution of SG (BET: $700 \mathrm{~m}^{2} / \mathrm{g}$ ) dispersed by different procedures. (a) Size distribution measured by laser diffraction spectroscopy plotted as the transformed distribution density $\left(\mathrm{q}^{3 *}\right)$. Weak (PS), moderate (RS) and intense (US) dispersion with increasing ultrasonic energies (indicated in the diagram) were employed. (b) Silica suspensions after five months (left $1 \mathrm{~J} / \mathrm{mL}$, middle $270 \mathrm{~J} / \mathrm{mL}$, and right $1440 \mathrm{~J} / \mathrm{mL}$ ).

The effect of increasing dispersion energy on particle size of PS, SG and FS, as measured by LD, is compared in Figure 7, which shows the trend analysis for the $x_{50,3}$ and $x_{99,3}$ quantiles of the volume weighted size distribution. Whereas the particle size of SG is not altered by increased dispersion energy, particle size of PS is constantly lowered. In the case of FS, only the $x_{50,3}$ value reflects the decrease in particle size, whereas the $x_{99,3}$ is inconsistent and shows an upwards trend demonstrating the coarsening or reagglomeration upon high USD energy. Figure 8 shows a comparison the stability of intensely dispersed silica types at $1440 \mathrm{~J} / \mathrm{mL}$ after long-term sedimentation ( 5 months). The different sediment degrees of silica types support the LD results and provide a subjective information about sedimentation velocity in the gravitational field of the earth.

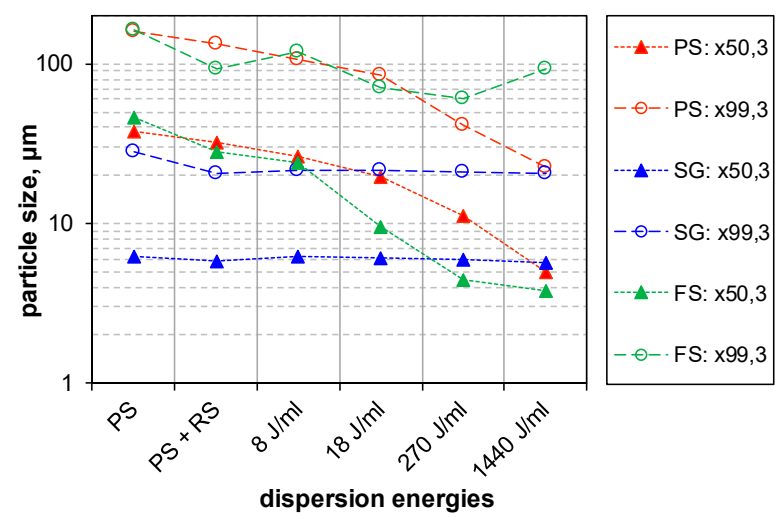

Figure 7. Particle size distribution of silica suspension after administration of increasing dispersion energy as measured by laser diffraction. Curves show the trends for the $x_{50,3}$ and $x_{99,3}$ quantiles of the volume weighted size distribution. USD energy density of ultrasonic treatment is indicated in $\mathrm{J} / \mathrm{mL}$. 


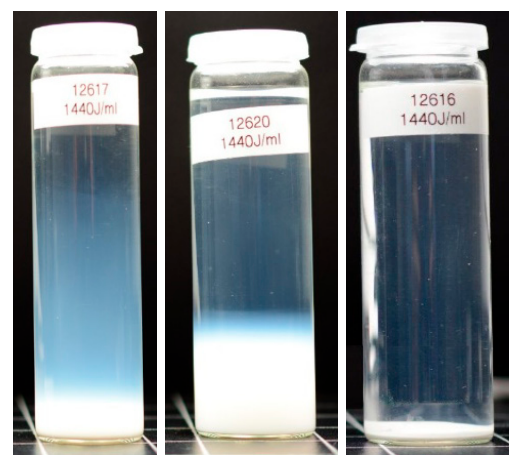

(a)

(b)

(c)

Figure 8. Intensely dispersed SAS samples (USD, $E_{V, \text { cal }}: 1440 \mathrm{~J} / \mathrm{mL}$ ) after long-term sedimentation (5 months): (a) PS; (b) FS; (c) SG.

Since LD is not sensitive for silica particles smaller than $1 \mu \mathrm{m}$ [68], the characterization of sub-micrometer particles $(1 \mathrm{~nm}-10 \mu \mathrm{m})$ was carried out with DLS. Data of three silica types (FS, SG, PS) was expressed as intensity-weighted size distribution, using the characteristic values mean size (xcum) and the polydispersity index (PDI) obtained by cumulant analysis. Figure $9 \mathrm{a}$ compares the as result calculated logarithmic normal distribution (LND) and shows the impact of $270 \mathrm{~J} / \mathrm{mL}$ and $1440 \mathrm{~J} / \mathrm{mL}$ on particle size. In Figure $9 \mathrm{~b}$ the Intensity-weighted transformed distribution density functions are shown. While the particle size of SG and FS remains nearly unchanged in the lower size range, the long-term sedimentation e cumulative size distribution curve of PS is shifted leftwards, indicating that particle size had shifted to submicron and nano range $(<1 \mu \mathrm{m})$. Fumed silica (FS) shows a minimal tendency to increase the size of submicron particles upon high energy density.

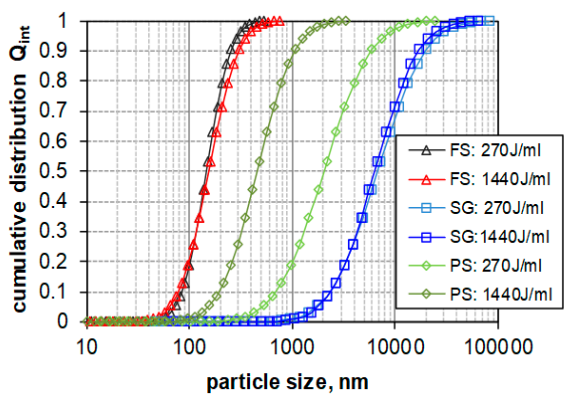

(a)

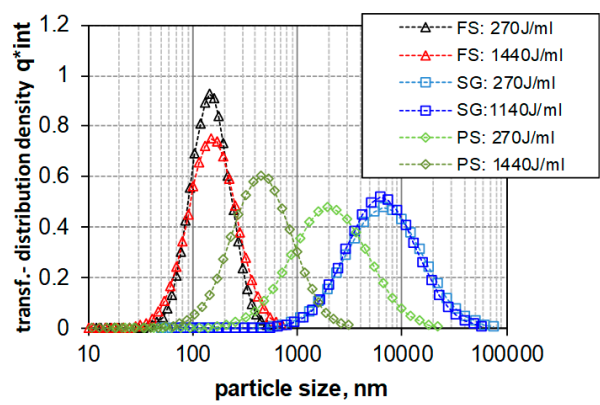

(b)

Figure 9. Particle size distribution (PSD) of amorphous silica suspensions dispersed by two different ultrasonic dispersion energy densities (270 and $1440 \mathrm{~J} / \mathrm{mL}$ ). PSD was measured by dynamic light scattering (DLS). FS: fumed silica, SG: gel silica, PS: precipitated silica. (a) Intensity-weighted sum functions for different energy density values. (b) Intensity-weighted transformed distribution density functions for different energy density values. Logarithmic normal distribution.

Figure 10a shows the granulometric state of colloidal silica (CS) over the full range of dispersion energies as used in Figure 7. While stirring (PS, PS + RS) had no effect on particle size, ultrasonic treatment surprisingly led to a larger and broader PSD indicated by an increase in hydrodynamic size and PDI. The effect started at a low energy density of $8 \mathrm{~J} / \mathrm{mL}$ and was found to be strongly augmented upon higher USD energies. We found that wear particles from the sonotrode's tip, the larger of which appeared as a sediment at the bottom of the vial (Figure 10b), made a major contribution to this effect. Due to the strong light scattering properties of such metal particles (compared to the small and weakly scattering CS particles), even low amounts of wear particles contaminate the light optic measurements. If this increase of the mean particles size would be caused 
by agglomerated colloidal silica particles, they would be visible as a sediment layer after 5 months. In the case of silica gel scattering, intensity of the micrometer particles hides the contamination signals during measurement whereas, after settling, the contamination is embedded in the silica sediment.

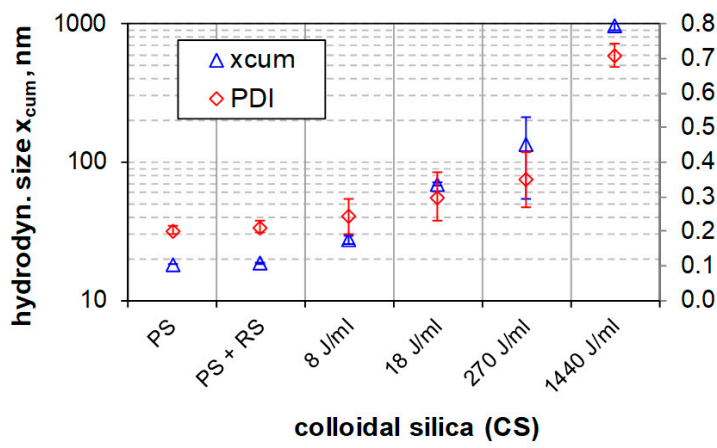

(a)

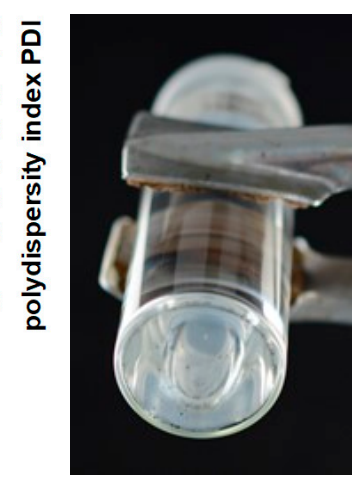

(b)

Figure 10. Particle size distribution of colloidal silica dispersed by different procedures measured by DLS. (a) Mean particle size (xcum) and corresponding polydispersity index (PDI) as determined with cumulant analysis. (b) Bottom view of a vial with an intensely dispersed colloidal silica sample $\left(E_{V, \text { cal }}\right.$ : $1440 \mathrm{~J} / \mathrm{mL}$ ) taken after 5 months of gravitational settling.

\subsubsection{Sample Contamination with Probe Sonication}

Figure 11a,b show the effect of high dispersion energy on the sonotrode's tip if delivered over prolonged period. Wear particles ablated from the tip contaminate suspension and can observed as a black sediment (i.e., coarse titanium particles) and/or as a well as a grey discoloration of the suspension (Figure 11c). Figure 12 shows a SEM picture of sonotrode abrasion particles collected from the bottom of silica suspension. As shown in a previous study, the abrasion of the ultrasonic probe and sample contamination occurs in the moment of ultrasonication; the number of particles increases linearly with time [20]. Furthermore, it was shown that in suspension of pyrogenic silica (PS, $1 \mathrm{wt} .-\%$ ) at a dispersion energy $>171 \mathrm{~J} / \mathrm{mL}$ sonotrode wear particles contribute to the PSD and interfere with the sample analysis by LD [20]. Nevertheless, this widespread sonicator type is superior to other indirect sonicator types (e.g., ultrasonic bath, cup horn) [36,69] due to its high effectiveness of USD and with regard to the best possible disintegration of agglomerates and aggregates in a short time [20]. Therefore, a restriction of the USD energy appears reasonable. To remove larger particles at lower dispersion energy, e.g., from PS suspensions, we developed a dispersion protocol combining stirring, USD and filtration steps (see Section 3.3).

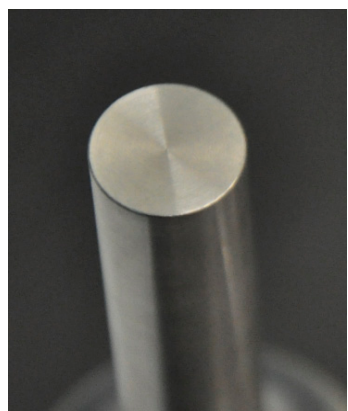

(a)

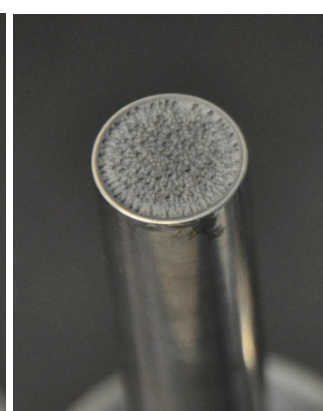

(b)

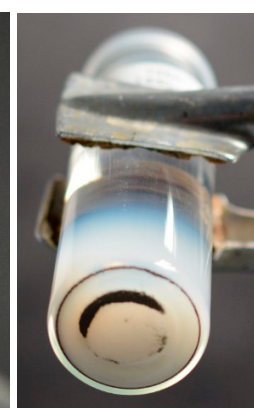

(c)

Figure 11. Comparison of new and used sonotrode with sonotrode abrasion as a consequence of long ultrasonic dispersion time $(\mathbf{a}, \mathbf{b})$; sonotrode abrasion sediment on the bottom of a precipitated silica suspension sample after high USD energy (c) (i.e., $E_{V, \mathrm{cal}}: 1440 \mathrm{~J} / \mathrm{mL}$ ). 


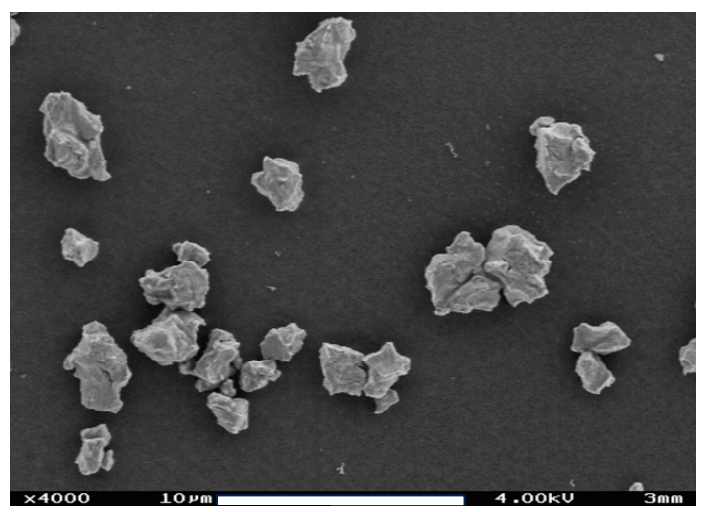

Figure 12. Scanning electron microscope image of wear particles from the sonotrode tip. Abrasion particles were collected from the sediment of a silica suspension sample after high USD energy (i.e., $E_{V, \text { cal }}: 1440 \mathrm{~J} / \mathrm{mL}$ ).

\subsection{Sample Preparation with Size-Selective Filtration}

Testing the in vitro toxicity of nanomaterials requires that the size distribution of particles in cell culture media is well defined. With respect to inhalation exposure, which may be tested by the alveolar macrophage assay [24], larger non-respirable coarse particles need to be removed so that a mass-per-volume- or surface-per-volume dose metrics can be applied [15]. Ideally, particle size distribution should reflect inhalable fractions with aerodynamic diameters smaller than $4 \mu \mathrm{m}$. However, as outlined above for paddle stirring (PS), this would require high ultrasonic energy and bears the risk of metal particle contamination (see Figures 11 and 12). To circumvent this risk, a size classification by controlled filtration (with $100 \%$ fines penetration) was developed, using a commercially available nylon gaze with a pore size of nominally $5 \mu \mathrm{m}$ (Bückmann, Germany). Figure 13 shows the grade efficiency function $T(x)$ demonstrating that glass spheres below $7 \mu \mathrm{m}$ can freely permeate the filter, whereas spheres larger than $15 \mu \mathrm{m}$ were retained.

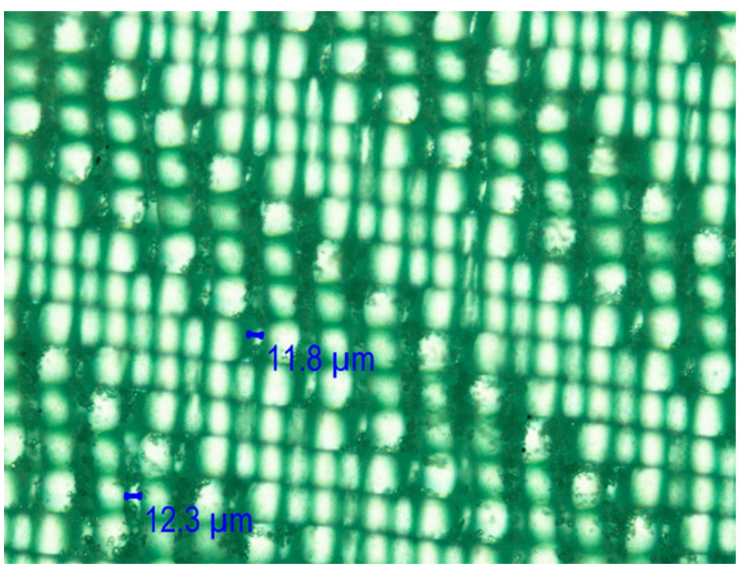

(a)

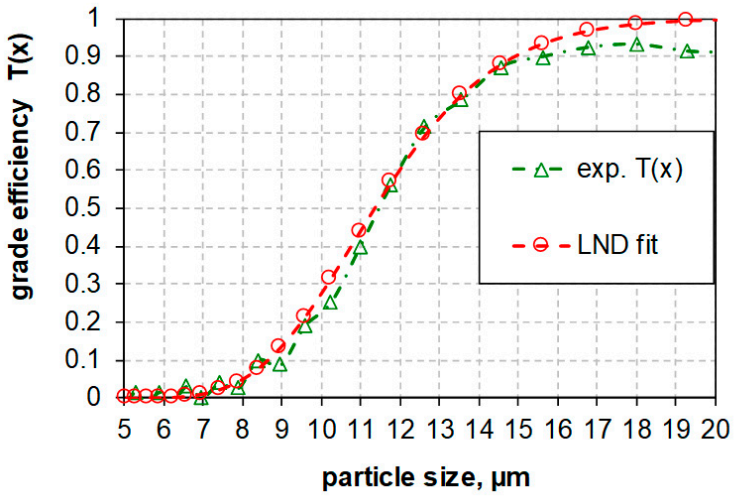

(b)

Figure 13. (a) Light microscope image of polymer gaze for size-selective suspension filtration and (b) $T(x)$ : grade efficiency function after gaze test filtration with glass spheres.

The theoretical volume weighted cumulative distribution function of the filtrate $Q_{3, \mathrm{f}}(x)$ was derived from the experimentally determined grade efficiency function $T(x)$ and the feed distribution $Q_{3, i}(x)$ :

$$
\Delta Q_{3, \mathrm{f}}(x)=(1-T(x)) \cdot\left(\frac{\Delta Q_{3, i}(x)}{1-\sum T(x) \cdot \Delta Q_{3, i}(x)}\right)
$$


In the next step ultrasonication and filtration where combined to prepare a suspension suitable for in vitro testing. The method is shown exemplarily for the PS used in this study: the powder was suspended $(1 \mathrm{mg} / \mathrm{mL})$ in de-ionized water by means of a magnet stirrer (700 rpm, $10 \mathrm{~min})$. Thereafter the PS sample was filtrated by gaze filter with a grade efficiency curve shown in Figure $13 \mathrm{~b}$ and a cut-off size of $11.5 \mu \mathrm{m}$. The filtrate of the silica sample was then dispersed with $E_{V, \mathrm{cal}}: 18 \mathrm{~J} / \mathrm{mL}$ and $E_{V \text {,cal }}: 270 \mathrm{~J} / \mathrm{mL}$. Results were expressed in Figure $14 \mathrm{a}$ as cumulative particle volume curves (Q3, green curve) and compared to the effects of progressive dispersion energy on the size distribution of non-filtered PS (red curve).

Figure 14 a shows the advantage of combined moderate ultrasonication by $270 \mathrm{~J} / \mathrm{mL}$ with filtration (green line) to remove particles larger than $11 \mu \mathrm{m}$ in comparison with the high ultrasonic energy result (red line), including possible sample pollution. LD results (Figure 14b) show that low energies (i.e., weak dispersion (PS), moderate dispersion (RS) without ultrasonication) leave a considerable amount of micrometer-sized agglomerates in the suspension, whereas ultrasonic dispersion with 8,18 , 270 and $1440 \mathrm{~J} / \mathrm{mL}$ progressively reduced micrometer-sized agglomerates.

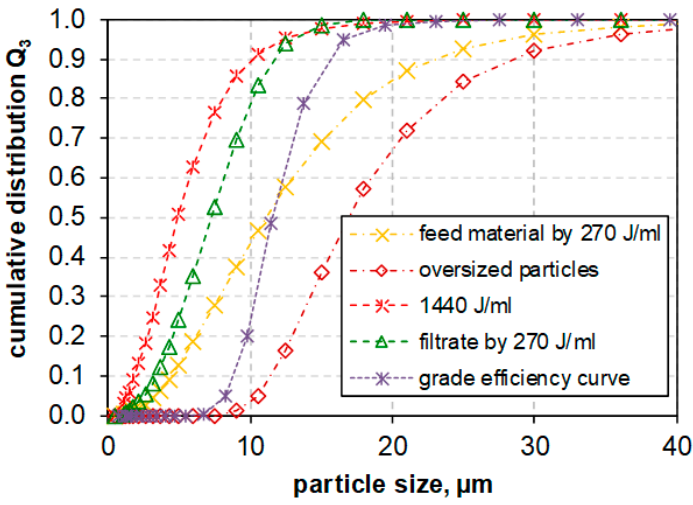

(a)

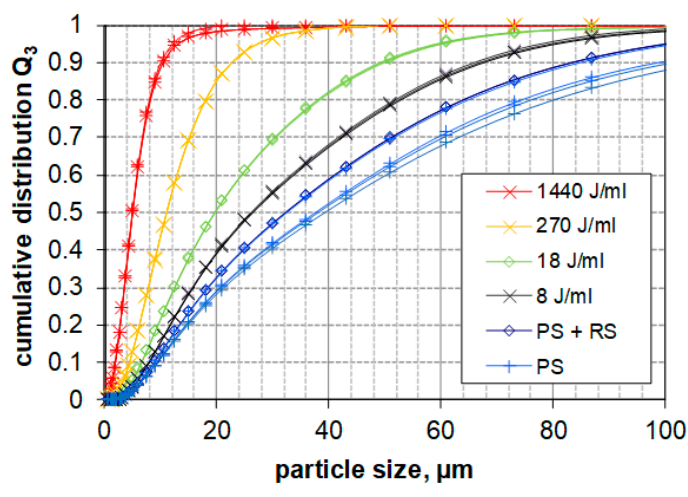

(b)

Figure 14. (a) filter grade efficiency curve and calculated results for penetrated (filtrate) and retained particle size distributions from feed size distribution (yellow) in comparison to not filtered but with $1440 \mathrm{~J} / \mathrm{mL}$ dispersed sample (b) Evolution of PSD during ultrasonication of precipitated silica $\left(440 \mathrm{~m}^{2} / \mathrm{g}\right)$; cumulative distribution functions measured by LD.

\section{Conclusions}

The effect of dispersion energy on particle size distribution of nanomaterial suspensions depends not only on a defined dispersion procedure (e.g., dispersion time, sample volume) but also on the silica types (e.g., morphology).

Ultrasonic dispersion energy density is a main parameter for comparability of sample preparation protocols. Sonication is limited by sample pollution with wear particles from the probe. Therefore, upper limit dispersion energy density values must be determined. In the case of silica it is recommended to apply dispersion energy density only up to $300 \mathrm{~J} / \mathrm{mL}$.

The resulting particle size distributions strongly depend on the type of silica. Fumed SAS reach PSDs in the submicron range even at low values of ultrasonic energy density; continued sonication leads to a steady, yet slight size reduction. Gel and colloidal SAS are hardly or even adversely affected by increasing ultrasonic dispersion energies. The PSDs of precipitated SAS strongly depends on the increasing ultrasonic dispersion energy, changing constantly to smaller sizes.

Additional size-selective filtration can remove the large and settling particles without the risk of sample contamination by too high ultrasonic energy dispersion. A combination with the above-described ultrasonic dispersion provides a general SOP for the preparation of well-defined suspensions of SAS nanoparticles for in vitro toxicological tests. 
Author Contributions: R.R.R.M. is the main author who largely conducted the experimental investigations (including design of experiments and data analysis) and contributed most to the manuscript. F.B. contributed to the development of the sample preparation procedures and the interpretation of the measurement data. He also critically reviewed the original draft of the manuscript. G.G.L. was involved as an expert for the material system, who helped to develop the methodology of sample preparation and measurement. M.W. developed the filtration method and wrote parts of the manuscript. M.S. supervised this study and prepared its basic design. In addition, he performed the characterization of the size-selective filter. He also wrote parts of the manuscript.

Funding: This research received no external funding.

Acknowledgments: The authors thank Evonik Resource Efficiency GmbH for providing silica samples and, phys.-chem. data.

Conflicts of Interest: The authors declare no conflict of interest.

\section{References}

1. Borm, P.J.A.; Robbins, D.; Haubold, S.; Kuhlbusch, T.; Fissan, H.; Donaldson, K.; Schins, R.; Stone, V.; Kreyling, W.; Lademann, J.; et al. The potential risks of nanomaterials: A review carried out for ECETOC. Part. Fibre Toxicol. 2006, 3, 11. [CrossRef] [PubMed]

2. Mogharabi, M.; Abdollahi, M.; Faramarzi, M.A. Toxicity of nanomaterials; an undermined issue. DARU J. Pharm. Sci. 2014, 22, 59. [CrossRef] [PubMed]

3. Fruijtier-Pölloth, C. The safety of nanostructured synthetic amorphous silica (SAS) as a food additive (E 551). Arch. Toxicol. 2016, 90, 2885-2916. [CrossRef] [PubMed]

4. Lorenz, C.; von Goetz, N.; Scheringer, M.; Wormuth, M.; Hungerbühler, K. Potential exposure of German consumers to engineered nanoparticles in cosmetics and personal care products. Nanotoxicology 2011, 5, 12-29. [CrossRef] [PubMed]

5. He, X.; Hwang, H.-M. Nanotechnology in food science: Functionality, applicability, and safety assessment. J. Food Drug Anal. 2016, 24, 671-681. [CrossRef] [PubMed]

6. Winkler, H.C.; Suter, M.; Naegeli, H. Critical review of the safety assessment of nano-structured silica additives in food. J. Nanobiotechnol. 2016, 14, 44. [CrossRef] [PubMed]

7. Retamal Marín, R.R.; Babick, F.; Stintz, M. Physico-chemical separation process of nanoparticles in cosmetic formulations. J. Phys. Conf. Ser. 2017, 838, 012004. [CrossRef]

8. Froggett, S.J.; Clancy, S.F.; Boverhof, D.R.; Canady, R.A. A review and perspective of existing research on the release of nanomaterials from solid nanocomposites. Part. Fibre Toxicol. 2014, 11, 17. [CrossRef] [PubMed]

9. Epstein, H.A.; Kielbassa, A. Nanotechnology in Cosmetic Products, Bio-Nanotechnology: A Revolution in Food. Biomed. Health Sci. 2013, 414-423. [CrossRef]

10. Wu, M.S.; Sun, D.S.; Lin, Y.C.; Cheng, C.L.; Hung, S.C.; Chen, P.K.; Yang, J.H.; Chang, H.H. Nanodiamonds protect skin from ultraviolet B-induced damage in mice. J. Nanobiotechnol. 2015, 13, 35. [CrossRef] [PubMed]

11. Lin, W.; Huang, Y.W.; Zhou, X.D.; Ma, Y. In vitro toxicity of silica nanoparticles in human lung cancer cells. Toxicol. Appl. Pharmacol. 2006, 217, 252-259. [CrossRef] [PubMed]

12. Foged, C.; Brodin, B.; Frokjaer, S.; Sundblad, A. Particle size and surface charge affect particle uptake by human dendritic cells in an in vitro model. Int. J. Pharm. 2005, 298, 315-322. [CrossRef] [PubMed]

13. Noël, A.; Maghni, K.; Cloutier, Y.; Dion, C.; Wilkinson, K.J.; Hallé, S.; Tardif, R.; Truchon, G. Effects of inhaled nano- $\mathrm{TiO}_{2}$ aerosols showing two distinct agglomeration states on rat lungs. Toxicol. Lett. 2012, 214, 109-119. [CrossRef] [PubMed]

14. Yang, H.; Wu, Q.Y.; Li, M.Y.; Lao, C.S.; Zhang, Y.J. Pulmonary Toxicity in Rats Caused by Exposure to Intratracheal Instillation of $\mathrm{SiO}_{2}$ Nanoparticles. Biomed. Environ. Sci. 2017, 30, 264-279. [CrossRef] [PubMed]

15. Wiemann, M.; Vennemann, A.; Sauer, U.G.; Wiench, K.; Ma-Hock, L.; Landsiedel, R. An in vitro alveolar macrophage assay for predicting the short-term inhalation toxicity of nanomaterials. J. Nanobiotechnol. 2016, 14, 16. [CrossRef] [PubMed]

16. Marvanová, S.; Kulich, P.; Skoupý, R.; Hubatka, F.; Ciganek, M. Size-segregated urban aerosol characterization by electron microscopy and dynamic light scattering and influence of sample preparation. Atmos. Environ. 2018. [CrossRef]

17. Benelli, G. Mode of action of nanoparticles against insects. Environ. Sci. Pollut. Res. 2018, 25, $12329-12341$. [CrossRef] [PubMed] 
18. Babick, F. Suspensions of colloidal particles and aggregates. In Particle Technology Series; Valverde Millán, J.M., Ed.; Springer: Berlin/Heidelberg, Germany, 2016; Volume 20, ISBN 978-3-319-30661-2.

19. Babick, F.; Schieß, K.; Stintz, M. Characterization of Pyrogenic Powders with Conventional Particle Sizing Technique: I. Prediction of Measured Size Distributions. Part. Part. Syst. Charact. 2012, 29, 104-115. [CrossRef]

20. Retamal Marín, R.R.; Babick, F.; Stintz, M. Ultrasonic dispersion of nanostructured materials with probe sonication-Practical aspects of sample preparation. Powder Technol. 2017, 318, 451-458. [CrossRef]

21. Oberdörster, G.; Maynard, A.; Donaldson, K.; Castranova, V.; Fitzpatrick, J.; Ausman, K.; Carter, J.; Karn, B.; Kreyling, W.; Lai, D.; et al. Principles for characterizing the potential human health effects from exposure to nanomaterials: Elements of a screening strategy. Part. Fibre Toxicol. 2005, 2, 8. [CrossRef] [PubMed]

22. Passagne, I.; Morille, M.; Rousset, M.; Pujalté, I.; L'Azou, B. Implication of oxidative stress in size-dependent toxicity of silica nanoparticles in kidney cells. Toxicology 2012, 299, 112-124. [CrossRef] [PubMed]

23. Taurozzi, J.; Hackley, V.; Wiesner, M. Ultrasonic dispersion of nanoparticles for environmental, health and safety assessment-Issues and recommendations. Nanotoxicology 2011, 5, 711-729. [CrossRef] [PubMed]

24. Veith, L.; Vennemann, A.; Breitenstein, D.; Engelhard, C.; Wiemann, M.; Hagenhoff, B. Detection of $\mathrm{SiO}_{2}$ nanoparticles in lung tissue by ToF-SIMS imaging and fluorescence microscopy. Analyst 2017, 142, 2631. [CrossRef] [PubMed]

25. Maier, M.; Hannebauer, B.; Holldorff, H.; Albers, P. Does Lung Surfactant Promote Disaggregation of Nanostructured Titanium Dioxide? J. Occup. Environ. Med. 2006, 48, 1314-1320. [CrossRef] [PubMed]

26. Bakand, S.; Hayes, A.; Dechsakulthorn, F. Nanoparticles: A review of particle toxicology following inhalation exposure. Inhal. Toxicol. 2012, 24, 125-135. [CrossRef] [PubMed]

27. Clippinger, A.J.; Ahluwalia, A.; Allen, D.; Bonner, J.C.; Casey, W.; Castranova, V.; David, R.M.; Halappanavar, S.; Hotchkiss, J.A.; Jarabek, A.M.; et al. Expert consensus on an in vitro approach to assess pulmonary fibrogenic potential of aerosolized nanomaterials. Arch. Toxicol. 2016, 90, 1769-1783. [CrossRef] [PubMed]

28. Nemmar, A.; Hoylaerts, M.F.; Hoet, P.H.M.; Vermylen, J.; Nemery, B. Size effect of intratracheally instilled particles on pulmonary inflammation and vascular thrombosis. Toxicol. Appl. Pharmacol. 2003, 186, 38-45. [CrossRef]

29. Arick, D.Q.; Choi, Y.H.; Kim, H.C.; Won, Y. Effects of nanoparticles on the mechanical functioning of the lung. Adv. Colloid Interface Sci. 2015, 225, 218-228. [CrossRef] [PubMed]

30. ISO. Nanotechnologies - Health and Safety Practices in Occupational Settings Relevant to Nanotechnologies; TC229, ISO/TR 12885; ISO: Geneva, Switzerland, 2008.

31. European Commission. Commission Recommendation of 18 October 2011 on the Definition of Nanomaterial (2011/696/EU). Off. J. Eur. Union 2011, 54, 38-40.

32. Linsinger, T.P.J.; Roebben, G.; Gilliland, D.; Calzolai, L.; Rossi, F.; Gibson, N.; Klein, C. Requirements on Measurements for the Implementation of the European Commission Definition of the Term 'Nanomaterial'; Publications Office of the European Union: Luxembourg, 2012. [CrossRef]

33. Jensen, K.; Kembouche, Y.; Christiansen, E.; Jacobsen, N.; Wallin, H.; Guiot, C.; Spalla, O.; Witschger, O. The Generic NANOGENOTOX Dispersion Protocol: Final Protocol for Producing Suitable Manufactured Nanomaterial Exposure Media. NANOGENOTOX Joint Action, European Commission. 2011. Available online: www.nanogenotox.eu/files/PDF/web\%20nanogenotox\%20dispersion\%20protocol.pdf (accessed on 20 June 2018).

34. OECD. Guidelines for the Testing of Chemicals, Section 3 Test No. 318: Dispersion Stability of Nanomaterials in Simulated Environmental Media; OECD Publishing: Washington, DC, USA, 2017; ISBN 9789264284142.

35. Rasmussen, K.; Mech, A.; Mast, J.; de Temmerman, P.-J.; Waegeneers, N.; van Steen, F.; Pizzolon, J.C.; de Temmerman, L.; van Doren, E.; Jensen, K.A.; et al. Synthetic Amorphous Silicon Dioxide (NM-200, NM-201, NM-202, NM-203, NM-204): Characterisation and Physico-Chemical Properties; Report EUR 26046; European Commission: Brussels, Belgium, 2013.

36. Hartmann, N.; Jensen, K.; Baun, A.; Rasmussen, K.; Rauscher, H.; Tantra, R.; Cupi, D.; Gilliland, D.; Pianella, F.; Sintes, J.R. Techniques and Protocols for Dispersing Nanoparticle Powders in Aqueous Media-Is there a Rationale for Harmonization? J. Toxicol. Environ. Health B 2015, 18, 299-326. [CrossRef] [PubMed]

37. Pohl, M.; Schubert, H.; Schuchmann, H. Herstellung stabiler Dispersionen aus pyrogener Kieselsäure. Chem. Ing. Tech. 2005, 77, 258-262. [CrossRef] 
38. Wengeler, R.; Ruslim, F.; Nirschl, H.; Merkel, T. Dispergierung feindisperser Agglomerate mit Mikro-Dispergierelementen. Chem. Ing. Tech. 2004, 76, 659-662. [CrossRef]

39. Wengeler, R.; Teleki, A.; Vetter, M.; Pratsinis, S.; Nirschl, H. High-pressure liquid dispersion and fragmentation of flame-made silica agglomerates. Langmuir 2006, 22, 4928-4935. [CrossRef] [PubMed]

40. Sauter, C.; Schuchmann, H. High pressure for dispersing and deagglomerating nanoparticles in aqueous solutions. Chem. Eng. Technol. 2007, 30, 1401-1405. [CrossRef]

41. Bałdyga, J.; Makowski, Ł.; Orciuch, W.; Sauter, C.; Schuchmann, H. Agglomerate dispersion in cavitating flows. Chem. Eng. Res. Des. 2009, 87, 474-484. [CrossRef]

42. Tantra, R. Nanomaterial Characterization: An Introduction; Wiley: Hoboken, NJ, USA, 2016; ISBN 9781118753460.

43. Pradhan, S.; Hedberg, J.; Wold, E.B.S.; Wallinder, I.O. Effect of sonication on particle dispersion, administered dose and metal release of non-functionalized, non-inert metal nanoparticles. J. Nanopart Res. 2016, 18, 285. [CrossRef] [PubMed]

44. Taurozzi, J.; Hackley, V.; Wiesner, M. Preparation of Nanoparticle Dispersions from Powdered Material using Ultrasonic Disruption. NIST Spec. Publ. 2012. [CrossRef]

45. Bihari, P.; Vippola, M.; Schultes, S.; Praetner, M.; Khandoga, A.G.; Reichel1, C.A.; Coester, C.; Tuomi, T.; Rehberg, M.; Krombach, F. Optimized dispersion of nanoparticles for biological in vitro and in vivo studies. Part. Fibre Toxicol. 2008, 5, 14. [CrossRef] [PubMed]

46. Mandzy, N.; Grulke, E.; Druffel, T. Breakage of $\mathrm{TiO}_{2}$ agglomerates in electrostatically stabilized aqueous dispersions. Powder Technol. 2005, 160, 121-126. [CrossRef]

47. Pohl, M.; Hogekamp, S.; Hoffmann, N.; Schuchmann, H. Dispergieren und Desagglomerieren von Nanopartikeln mit Ultraschall. Chem. Ing. Tech. 2004, 76, 392-396. [CrossRef]

48. Napierska, D.; Thomassen, L.C.J.; Lison, D.; Martens, J.A.; Hoet, P.H. The nanosilica hazard: Another variable entity. Part. Fibre Toxicol. 2010, 7, 39. [CrossRef] [PubMed]

49. Brinker, C.F.; Schrerer, G.W. Sol-Gel Science. The Physics and Chemistry of Sol-Gel Processing, 2nd ed.; Academic Press: London, UK, 1990; ISBN 9780121349707.

50. Albers, P.; Maier, M.; Reisinger, M.; Hannebauer, B.; Weinand, R. Physical boundaries within aggregates-differences between amorphous, para-crystalline, and crystalline Structures. Cryst. Res. Technol. 2015, 50, 846-865. [CrossRef]

51. Brunauer, S.; Emmett, P.H.; Teller, E. Adsorption of Gases in Multimolecular Layers. J. Am. Chem. Soc. 1938, 309-319. [CrossRef]

52. ISO 9277:2010. Determination of the Specific Surface Area of Solids by Gas Adsorption-BET Method; ISO: Geneva, Switzerland, 2010.

53. Hosokawa, M.; Nogi, K.; Naito, M.; Yokoyama, T. Nanoparticle Technology Handbook; Elsevier Science: New York, NY, USA, 2007; ISBN 978-0-444-53122-3.

54. Retamal Marín, R.R.; Babick, F.; Hillemann, L. Zeta potential measurements for non-spherical colloidal particles-Practical issues of characterisation of interfacial properties of nanoparticles. Colloids Surf. A 2017, 532, 516-521. [CrossRef]

55. Karina Maria Paciejewska, Untersuchung des Stabilitätsverhaltens von binären kolloidalen Suspensionen, Ph.D. Thesis, Technische Universität Dresden, Dresden, Germany, December 2010. Available online: http:/ /d-nb.info/1019001267/34 (accessed on 20 June 2018).

56. European Pharmacopoeia: Supplement 5.7, Band 5 von European Pharmacopoeia: Supplement, 5th ed.; Convention on the Elaboration of a European Pharmacopoeia, 4805-4806; Council of Europe: Strasbourg, France, 2006.

57. Hauptmann, P.; Sorge, G. Ultraschall in Wissenschaft und Technik; Durchschnittliche Kundenbewertung: Leipzig, Germany, 1985; ISBN 0-906674-38-7.

58. Kusters, K.; Pratsinis, S.; Thoma, S.; Smith, D. Ultrasonic fragmentation of agglomerate powders. Chem. Eng. Sci. 1993, 48, 4119-4127. [CrossRef]

59. Aoki, M.; Ring, T.; Haggerty, J. Analysis and modeling of the ultrasonic dispersion technique. Adv. Ceram. Mater. 1987, 2, 209-212. [CrossRef]

60. Etzler, F.M.; Deanne, R. Particle Size Analysis: A Comparison of Various Methods II. Part. Part. Syst. Charact. 1997, 14, 278-282. [CrossRef]

61. Bayat, H.; Rastgo, M.; Zadeh, M.M.; Vereecken, H. Particle size distribution models, their characteristics and fitting capability. J. Hydrol. 2015, 529, 872-889. [CrossRef] 
62. Marton, L.; Marton, C. Methods of Experimental Physics: Ultrasonics; Academic Press: Cambridge, MA, USA, 1981; ISBN 0-12-475961-0.

63. Raman, V.; Abbas, A. Experimental investigations on ultrasound mediated particle breakage. Ultrason. Sonochem. 2008, 15, 55-64. [CrossRef] [PubMed]

64. Raso, J.; Mañas, P.; Pagán, R.; Sala, F. Influence of different factors on the output power transferred into medium by ultrasound. Ultrason. Sonochem. 1999, 5, 157-162. [CrossRef]

65. Edmond, P.D. Methods in Experimental Physics; Elsevier: New York, NY, USA, 1981; Volume 19, ISBN 978-0-12-475961-9.

66. Bhatia, A.B. Ultrasonic Absorption. An Introduction to the Theory of Sound Absorption and Dispersion in Gases, Liquids, and Solids; Oxford University Press: New York, NY, USA, 1967; ISBN 9780486649177.

67. ISO 9276-1:1998. Representation of Results of Particle size Analysis_Part 1: Graphical Representation; ISO: Geneva, Switzerland, 1998.

68. Kuchenbecker, P.; Gemeinert, M.; Rabe, T. Interlaboratory study of particle size distribution measurements by laser diffraction. Part. Part. Syst. Charact. 2012, 29, 304-310. [CrossRef]

69. Mawson, R.; Rout, M.; Ripoll, G.; Swiergon, P.; Singh, T.; Koerzer, K.; Juliano, P. Production of particulates from transducer erosion: Implications on food safety. Ultrason. Sonochem. 2014, 21, 2122-2130. [CrossRef] [PubMed]

(C) 2018 by the authors. Licensee MDPI, Basel, Switzerland. This article is an open access article distributed under the terms and conditions of the Creative Commons Attribution (CC BY) license (http://creativecommons.org/licenses/by/4.0/). 